\title{
International Day of the Tropics: Towards a better global future
}

\author{
Sandra Harding
}

Vice Chancellor and President, James Cook University, Australia and Singapore

\section{Gillian Bird}

Permanent Representative and Ambassador of Australia to the United Nations, Australia and USA

\section{Elizabeth Losos}

Organisation for Tropical Studies, USA and Costa Rica

\section{Rose Aderolili}

Otino International, Uganda and International

\section{Peter Hotez}

National School of Tropical Medicine, Baylor College of Medicine, USA

\section{Abstract}

At a time of great global change, and as the world begins to implement a redefined global development agenda, is timely to consider the importance of the tropical region and its role in our global future. The 'International Day of the Tropics', inaugurated in early June this year and celebrated for the first time on June 29, 2016, shines a light on the significant challenges and opportunities faced by nations of the Tropics and the global implications of the rapid changes the region is experiencing. This paper summarises discussions held at the United Nations in New York on that inaugural International Day of the Tropics. 


\section{Introduction: the Inaugural International Day of the Tropics, United Nations, New York}

$\mathrm{T}$

The inaugural International Day of the Tropics took place on the anniversary of the delivery of the first State of the Tropics report in 2014 (State of the Tropics, 2014). Nobel Laureate Aung San Suu Kyi launched the report in Yangon, Myanmar with simultaneous events held in Singapore and Australia.

To celebrate the inaugural International Day of the Tropics, a side event hosted by the Missions to the United Nations of Australia, Maldives and Fiji, explored the important challenges and opportunities for the Tropics. This paper brings together perspectives from members of the Invited Panel of Experts and includes voices from across the Tropics from experts in development, the environment, economics and health to discuss the challenges and opportunities for the tropical world.

\section{Her Excellency Gillian Bird}

\section{Australian Permanent Representative and Ambassador to the United Nations}

\section{'Tropical challenges require Tropical solutions'}

On 14 June 2016 the United Nations General Assembly adopted, by consensus, a resolution designating 29 June as the International Day of the Tropics. There was widespread support for the initiative with seventy-four countries co-sponsoring the resolution. The message that the Tropics will be critical to global prosperity and that there are opportunities for all countries to further collaborate and learn from each other resonated broadly.

The International Day of the Tropics initiative will provide a platform and catalyst to explore the challenges facing the region and the unique characteristics, dynamics and capacities of this increasingly important part of the world. It will also serve to highlight opportunities for business, academia, civil society and governments to collaborate and share knowledge, and to develop adaptive and relevant services, products, innovations and technologies for the Tropics.

The progress we make together in harnessing the possibilities and addressing the challenges of tropical regions will play an important role in successfully achieving the United Nations Sustainable Development Goals over the next fifteen years. The International Day of the Tropics serves not only to bring all actors together, but to remind them that tropical challenges require tropical solutions.

\section{Celebrating the inaugural International Day}


The inaugural International Day of the Tropics provided a platform for various societies and peoples of the tropics to reflect upon what the day meant for them. Below are quotations from two Permanent Representatives of the United Nations who spoke at the inaugural event and have granted permission for use of their voices to add to this paper.

His Excellency, Mr Ahmed Sareer, Ambassador and Permanent Representative of the Maldives was able to provide a unique perspective from the island nation:

When we think about the Tropics, we tend to envision the sun all year around, a nice balmy breeze and perhaps a white beach and clear warm waters. We most often see the natural beauty of these places. But it is the underlying endurance and resilience of the people of these places that turn the often daunting challenges into enormous opportunities.

Similarly, His Excellency, Mr Peter Thomson, Permanent Representative and Ambassador of Fiji as well as incoming President of the United Nations General Assembly, recalled his experiences with tropical development:

Appropriate infrastructure for the Tropics is essential. Designs for water and sanitation systems imported from outside the region are often not appropriate for warm, tropical storm-prone areas.

In addition to the national representatives present at the inaugural International Day of the Tropics, a number of academic experts were present to provide their perspectives.

\section{Dr Elizabeth Losos}

\section{President and CEO of the Organisation for Tropical Studies}

\section{Diversity, connectivity and dynamism}

The Tropics contain some of the most extraordinary ecosystems on this planet, primarily because of their tremendous biological diversity. As a point of illustration, 100 hectares of rainforest in the Ecuadorian Amazon can contain more than 1200 different tree species, which is almost twice as many tree species as can be found in total on continental United States and Canada.

Managing such diverse ecosystems is challenging, in part because these tropical natural and human systems have especially interconnected and complex webs of relationships. If one element is affected, the cascading impact can be profound, and often surprising, throughout the ecosystem.

For example, tropical forests serve as one of the most important carbon sinks in the world, absorbing more carbon dioxide every year than any other terrestrial ecosystem. Yet recent research has shown that as temperatures get warmer - and in particular, as nighttime 
temperature does not cool down - and as droughts becomes stronger, tropical rainforests become less capable of absorbing carbon from the atmosphere. Simply put, warmer and drier conditions cause tropical trees to 'respire' more; their ability to photosynthesize cannot keep pace. It is possible that, if these trends continue, someday tropical forests will become a carbon source rather than sink - thus further contributing to global warming. The health of tropical forests and the climate are inextricably linked, with both influencing economic development, food security, migration and international conflict.

On the bright side, recent scientific evidence has demonstrated that tropical forests can regenerate more quickly than previously thought. With concerted management efforts, reforestation has the potential to restore a great deal of the damaged biological diversity and productivity of tropical ecosystems, and contribute importantly to mitigating climate change.

\section{Dr Rose Aderolili \\ Chief Economist, Otino International}

\section{Potential of a young and dynamic Africa}

The African continent accounts for a huge part of the land area of the Tropics and has an important global role to play. The tropical nations of Africa are currently experiencing some of the fastest population and economic growth rates in the world. According to the State of the Tropics project, population growth in Central and Southern Africa is just under 3\% per annum compared with 1.4\% globally. Similarly, economic growth since 2010 has remained around 6\% per annum, much greater than the global rate of just over 3\% (State of the Tropics, 2014).

We need to consider how we take advantage of the booming population and the implications for human capital development. This young population is an incredible resource but we must ensure that appropriate education provides the necessary skills to provide a demographic dividend. There is still much work to be done, not just to get children to school but also to ensure they have resources and quality education. Uganda for example, comprises a very young and unskilled population with $40 \%$ below fifteen years and $70 \%$ below the age of thirty. Most have primary school education but this does not provide the necessary skills and knowledge to fully engage with a modern, technological economy.

Resources are required to continue to promote economic growth and provide jobs for this young labour force, but it must be done sustainably and not through reckless use of natural resources. Already the impacts of climate change and land degradation are being felt in many parts of tropical Africa; flood prone areas are experiencing unprecedented drought conditions and floods are occurring in places they never have before. 
There are huge opportunities for new technologies in Africa, particularly in renewable energy many populations still have energy access rates lower than $50 \%$; but the enabling education and skills base must be in place in order to take advantage of this opportunity. Africa is critical to the achievement of the United Nations 2030 Agenda for Sustainable Development and resources must be allocated accordingly.

\section{Professor Peter Hotez \\ Dean of the National School of Tropical Medicine, Baylor College of Medicine}

\section{Tropical health in the Anthropocene}

Health underpins all social and economic development and is linked to many aspects of change being experienced across the Tropics. Through the Millennium Development Goals and the backing of the G7 nations there have been huge global health improvements across the Tropics including declining malaria rates and deaths from HIV/AIDS, rising vaccinations and reduced incidence in many neglected tropical diseases (NTDs) such as elephantiasis, river blindness, and trachoma.

However, there is now a counterbalance to those successes. Due to a new set of global forces affecting the Tropics, neglected and emerging diseases such as Ebola, coronavirus infection and other zoonoses, and vector-borne diseases like Dengue, Zika, leishmaniasis, and schistosomiasis pose a huge threat in a world increasingly modified by humans. Deforestation, climate change, and large scale infrastructure projects such as dams, urbanization, and mass migrations, including those resulting from conflict zones, have seen the rise of the Anthropocene, a period where human activity is the dominant influence on tropical climates and the environment (Hotez, 2016a). Two key consequences of these Anthropocene forces are: 1) an expansion of emerging and neglected diseases in tropical zones, such as Ebola in West Africa, arboviruses in the Americas, and the rise schistosomiasis in sub-Saharan Africa, and 2) the creation of new mini"hot-zones" associated with the emergence of tropical diseases in new areas. Included among the new twenty-first century hot-zones are Southern Europe, the Middle East and North Africa, Central Asia, and even northern Australia and the United States Gulf Coast and Florida.

In addition to the Anthropocene we also have to consider a new flavor to twenty-first century poverty. Poverty is a potent driver of disease and is central to the rise of neglected tropical diseases. Our new finding is that most of the poverty-related diseases are found among impoverished populations living in a wealthier group of twenty (G20) nations. ${ }^{1}$ I have given the

\footnotetext{
${ }^{1}$ Members of the G20 (group of twenty) wealthy nations include: Argentina, Australia, Brazil, Canada, China, France, Germany, India, Indonesia, Italy, Japan, Republic of Korea, Mexico, Russia, Saudi Arabia, South Africa, Turkey, the United Kingdom, the United States, as well as the European Union.
} 
term "blue marble health" to reflect this changing geopolitical landscape of disease (Hotez, 2016b).

What all this means is that medical research has to operate within a multidisciplinary environment, working with lawyers, social scientists, environmentalists and a range of other disciplines to explore the interconnectedness between human and natural systems. The expansion of tropical diseases in new and existing areas due to the Anthropocene and blue marble health represent complex problems that cannot be solved exclusively by traditional biomedical models. As academics we are going to need to leave our comfort zones and engage in dialogue with scholars in new disciplines. Universities will need to adapt and create new flexible structures that promote cross-disciplinary initiatives. In some ways the United Nations Sustainable Development Goals launched in 2015 represent a great framework to think about how we can restructure and reengage.

\section{Professor Sandra Harding Vice Chancellor and President, James Cook University}

\section{The State of the Tropics}

The State of the Tropics report (State of the Tropics, 2014) provides the essential backdrop to the commentary provided by the contributing experts. It is clear from the information provided above that understanding the Tropics is essential to understanding the trajectory of the world. Below, I further draw out some of the crucial findings of the State of the Tropics project (http://stateofthetropics.org/).

Population growth rates in the Tropics are around one third faster than the rest of the world, despite slowing over the past two decades. Currently just over three billion people $(42 \%$ of the world) live in a tropical country. Calculations based on median projections of mortality and fertility estimate that by the middle of this century, more than half the world's population will live in the Tropics including around $67 \%$ of children under fifteen years of age.

This demographic dividend means that the world's labour force will increasingly reside in the Tropics. Additionally, a growing middle class in countries and territories across the Tropics is driving strong demand for goods and services.

As stated above, health and wellbeing indicators have improved in recent decades, however, it must be noted that $65 \%$ of world's poorest people live in the Tropics; it accounts for over $70 \%$ of child and infant mortality; and still bears a disproportionate share of the global burden of malaria, HIVIAIDS, tuberculosis and dengue. 
The cultures of the Tropics are diverse and rich. In fact, most of the world's languages are spoken in a broad area on either side of the Equator - in Southeast Asia and the Pacific, India, Africa, and South America. Concentrations of linguistic diversity can be found in Papua New Guinea (820 languages); Indonesia (700 languages); India (447 languages); the Congo (242 languages); and Myanmar (100 languages). Other nations such as Vanuatu, Brazil and Indonesia also have rich linguistic diversity. There are more than 2000 languages spoken throughout Africa, compared with just over 200 in Europe.

Alongside growing and culturally diverse human populations, are the unique ecosystems of the Tropics. The world's Tropics host around $80 \%$ of the world' terrestrial biodiversity and over $95 \%$ of its coral reefs and mangrove forests. Most of the world's remaining primary forests are tropical. A greater proportion of species are considered threatened in the Tropics, even though fewer have been assessed.

Across all of these sectors lies the existential challenge presented by a changing climate. The predicted changes in climate are set to lead to conditions in the Tropics with no precedence. For equatorial regions there are no existing analogues for the climates predicted for the second half of this century. For instance, Singapore will not just be warmer than it is now, but warmer than anywhere on Earth with year round rainfall.

We now know that what happens in the Tropics will impact the rest of the world for decades to come. A United Nations 'International Day of the Tropics' means a focus on the Tropics - and this is critical to delivering the multifaceted United Nations 2030 Agenda for Sustainable Development.

\section{Conclusion}

The national representatives and experts involved in the inaugural 'International Day of the Tropics' event reinforced the idea that a focus on sustainable development across the Tropics is essential for an equitable, prosperous, sustainable and peaceful world.

The panel expressed the need for focused, multi-disciplinary research to address the unique knowledge needs of the Tropics. Building capacity of the research community of the Tropics will be an essential step in the development of this knowledge.

\section{References}

Hotez P.J. (2016a). Neglected tropical diseases in the anthropocene: The cases of Zika, Ebola, and other infections. PLOS Neglected Tropical Diseases, 10(4): 1-6

Hotez, P.J. (2016b). Blue marble health: An innovative plan for diseases of the poor amid wealth. Baltimore, MD: Johns Hopkins University Press. 
State of the Tropics (2014). State of the Tropics Report. James Cook University, Australia. Retrieved from: http://stateofthetropics.org/the-report

United Nations (2016). Resolution 70/267 - International Day of the Tropics. Retrieved from United Nations General Assembly, New York, website:

http://www.un.org/en/ga/search/view_doc.asp?symbol=A/RES/70/267. 